\title{
Spatial Profile of Excitatory and Inhibitory Synaptic Connectivity in Mouse Primary Auditory Cortex
}

\author{
Robert B. Levy and Alex D. Reyes \\ Center for Neural Science, New York University, New York, New York 10003
}

The role of local cortical activity in shaping neuronal responses is controversial. Among other questions, it is unknown how the diverse response patterns reported in vivo-lateral inhibition in some cases, approximately balanced excitation and inhibition (co-tuning) in others - compare to the local spread of synaptic connectivity. Excitatory and inhibitory activity might cancel each other out, or, whether one outweighs the other, receptive field properties might be substantially affected. As a step toward addressing this question, we used multiple intracellular recording in mouse primary auditory cortical slices to map synaptic connectivity among excitatory pyramidal cells and the two broad classes of inhibitory cells, fast-spiking (FS) and non-FS cells in the principal input layer. Connection probability was distance-dependent; the spread of connectivity, parameterized by Gaussian fits to the data, was comparable for all cell types, ranging from 85 to $114 \mu \mathrm{m}$. With brief stimulus trains, unitary synapses formed by FS interneurons were stronger than other classes of synapses; synapse strength did not correlate with distance between cells. The physiological data were qualitatively consistent with predictions derived from anatomical reconstruction. We also analyzed the truncation of neuronal processes due to slicing; overall connectivity was reduced but the spatial pattern was unaffected. The comparable spatial patterns of connectivity and relatively strong excitatoryinhibitory interconnectivity are consistent with a theoretical model where either lateral inhibition or co-tuning can predominate, depending on the structure of the input.

\section{Introduction}

Local synaptic connectivity is a salient feature of sensory cortex. Connections among nearby cells far outnumber thalamic afferents in thalamorecipient layers (LeVay, 1986; White, 1989; Peters and Payne, 1993; Peters et al., 1994). Because receptive field properties such as preferred stimulus orientation (in the visual system) or frequency (in the auditory system) are encoded in the spatial position of cortical neurons, local connectivity may significantly shape the representation of stimulus features (Douglas et al., 1995; Sompolinsky and Shapley, 1997; Shapley et al., 2007). Rodent primary auditory cortex (A1) is a good model for assessing the role of local connectivity, because it is arranged tonotopically; preferred frequency varies smoothly along the rostrocaudal axis (Sally and Kelly, 1988; Hackett et al., 2011; cf. Bandyopadhyay et al., 2010). Thus, the spatial spread of activity is closely related to neuronal frequency tuning curves.

Recent in vivo studies have yielded conflicting data on the tuning of excitatory and inhibitory input to neurons in A1. In some cases inhibition was more broadly tuned than excitation (Wu et al., 2008; Sun et al., 2010), suggesting that local inhibition

\footnotetext{
Received Sept. 23, 2011; revised Feb. 2, 2012; accepted Feb. 28, 2012.

Author contributions: R.B.L. and A.D.R. designed research; R.B.L. performed research; R.B.L. and A.D.R. analyzed data; R.B.L. and A.D.R. wrote the paper.

This work was supported by National Science Foundation Grant IOS-0718633 (to R.B.L.) and NIH Grant DC005787-06 (to A.D.R.). We thank Robert Shapley for discussion and comments on an early version of this manuscript.

Correspondence should be addressed to Robert B. Levy, New York University Center for Neural Science, 4 Washington Place, Room 809, New York, NY 10003. E-mail: rbl2@nyu.edu.

DOI:10.1523/JNEUROSCI.5158-11.2012

Copyright $\odot 2012$ the authors $\quad 0270-6474 / 12 / 325609-11 \$ 15.00 / 0$
}

sharpens frequency tuning. However, another group reported that inhibition and excitation are balanced (Wehr and Zador, 2003; Dorrn et al., 2010), in which case inhibition could alter the strength and timing of responses, but would not affect frequency tuning. Moreover, lateral inhibition might be either generated intracortically or inherited from earlier stages (Suga et al., 1975, 1997; Young and Brownell, 1976). To resolve these ambiguities, it is important to know the spatial extent of the local circuitry. Strong and wide-ranging inhibition of excitatory cells would be expected to produce lateral inhibition under a broad range of stimulus conditions, whereas strong recurrent excitation would make it unlikely that lateral inhibition could be generated intracortically. At present, however, the local connectivity in A1 is not well known. Most studies using dual intracellular recording have been restricted to closely neighboring cells $(<100 \mu \mathrm{m})$, and optical methods with sufficient resolution have only been applied to a limited range of cell types and in other sensory regions (Fino and Yuste, 2011; Nikolenko et al., 2011; Packer and Yuste, 2011).

Here we used dual intracellular recordings to map spatial profiles of synaptic connectivity between pyramidal $(\mathrm{P})$ cells and the two major classes of inhibitory cells in the main thalamorecipient layer of mouse A1. We also performed morphometric analysis to compare physiologically measured connectivity with the extent of neuronal arbors, and to assess the effect of slicing. The spatial extent of connectivity was similar for all cell types, while the strength and probability of P-interneuron connections were substantially greater than for P-P interconnections. In conjunction with our recent simulation-based results (Levy and Reyes, 2011), the data support a model where the cortex is functionally mallea- 
Table 1. Intrinsic membrane properties by cell type

\begin{tabular}{|c|c|c|c|c|c|c|c|c|c|c|c|}
\hline & \multicolumn{2}{|c|}{$\mathrm{P}, n=49$} & \multicolumn{2}{|c|}{ WTFS, $n=52$} & \multicolumn{2}{|c|}{$\mathrm{G} 42, n=26$} & \multicolumn{2}{|c|}{ WT non-FS, $n=57$} & \multicolumn{2}{|c|}{ GIN, $n=46$} & \multirow{2}{*}{$\begin{array}{l}p \text { (GIN versus } \\
\text { WT non-FS) }\end{array}$} \\
\hline & Mean & SD & Mean & SD & Mean & SD & Mean & SD & Mean & SD & \\
\hline Age, $d$ & 22.6 & 3.5 & 22.7 & 2.7 & 22.1 & 2.5 & 21.3 & 3.2 & 24.8 & 3.8 & $<0.001$ \\
\hline Max. firing rate, $\mathrm{Hz}$ & 44.7 & 18.9 & 201.7 & 44.7 & 229.1 & 50.7 & 89.3 & 48.4 & 96.9 & 51.8 & \\
\hline Resting $\mathrm{V}_{\mathrm{m}}, \mathrm{mV}$ & -66.5 & 5.6 & -68.0 & 6.4 & -67.8 & 6.1 & -65.6 & 6.7 & -61.9 & 6.8 & 0.01 \\
\hline $\mathrm{R}_{\mathrm{in}}, \mathrm{M} \Omega$ & 126.4 & 82.7 & 119.5 & 36.6 & 119.4 & 38.9 & 195.0 & 88.8 & 279.6 & 85.8 & $<0.001$ \\
\hline $\mathrm{tau}_{\mathrm{m}}, \mathrm{ms}$ & 18.4 & 4.2 & 8.6 & 3.3 & 8.1 & 1.9 & 15.7 & 6.7 & 16.5 & 5.2 & \\
\hline ISI(last) / ISI(first) & 3.64 & 1.48 & 1.27 & 0.39 & 1.29 & 0.35 & 3.24 & 1.65 & 4.83 & 2.90 & 0.01 \\
\hline AP width, ms & 1.20 & 0.20 & 0.48 & 0.10 & 0.48 & 0.10 & 0.98 & 0.32 & 0.91 & 0.38 & \\
\hline AHP time, ms & 31.6 & 9.5 & 3.5 & 1.6 & 4.5 & 3.2 & 12.4 & 9.7 & 32.7 & 17.5 & $<0.001$ \\
\hline AHP amplitude, $\mathrm{mV}$ & -17.1 & 3.6 & -16.5 & 3.4 & -15.1 & 5.3 & -13.5 & 3.9 & -11.4 & 2.7 & 0.003 \\
\hline $\mathrm{V}_{\text {thresh }}, \mathrm{mV}$ & -41.5 & 3.5 & -40.0 & 6.0 & -38.2 & 6.1 & -38.1 & 7.6 & -40.6 & 5.9 & 0.04 \\
\hline Rheobase I, nA & 0.09 & 0.04 & 0.20 & 0.08 & 0.20 & 0.10 & 0.13 & 0.00 & 0.06 & 0.05 & 0.01 \\
\hline
\end{tabular}

Values are derived from responses to hyperpolarizing and depolarizing current steps (compare Fig. 1B). Max., maximum; $\mathrm{R}_{\mathrm{in}}$, input resistance; tau ${ }_{m}$, membrane time constant; ISI(last)/ISI(first), degree of spike rate adaptation; $\mathrm{V}_{\text {thresh }}$, spike threshold. Other terms as defined in main text.

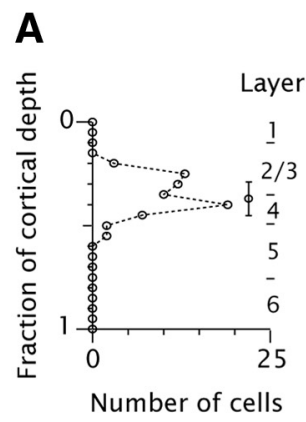

B i G42:

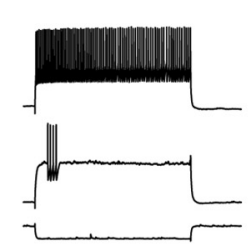

ii GIN:

a

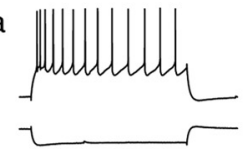

C

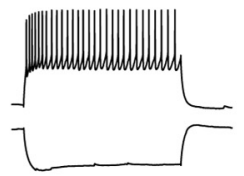

b
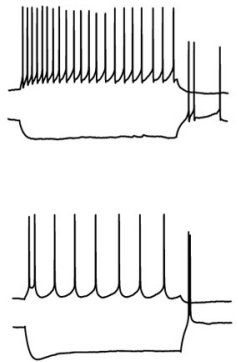

C - G42
- GIN
- WT
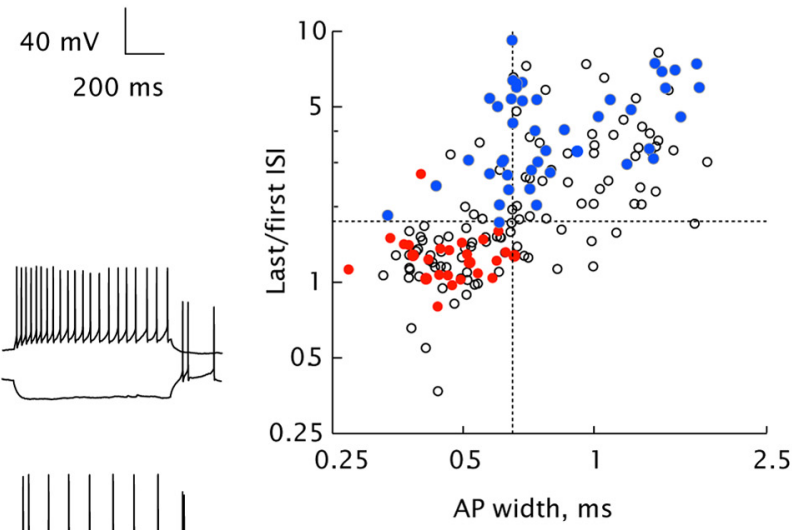

2.5

Figure 1. Characterization of recorded neurons. $A$, Location of somata as a fraction of total cortical depth (from pia to white matter), for all biocytin-filled cells ( $n=72$ ). Circle with bars denotes mean and SD (0.37 \pm 0.08). Laminar boundaries are indicated. $\boldsymbol{B}$, representative firing patterns in G42 (i) and GIN cells (ii). Injected currents were (in nA): $-0.05 / 0.15 / 0.35$ (i); $-0.05 / 0.15$ (iia); $-0.01 / 0.01$ (iib); $-0.08 / 0.13$ (iic); - 0.08/0.03 (iid). C, Action potential width (abscissa) versus degree of adaptation (last/first interspike interval (ISI), ordinate) for G42 (red circles), GIN (blue circles), and all inhibitory neurons in WT mice (open circles). Dashed lines denote boundaries for classifying WT cells as fast-spiking or non-fast-spiking (AP width 0.65 ms, ISI ratio 1.75 ).

ble, such that the degree of lateral inhibition is coupled to the spatial extent of afferent input.

\section{Materials and Methods}

Dissection and recording. Thalamocortical auditory slices from postnatal day (P) 18-29 wild-type (WT; Swiss-Webster), CB6-Tg(Gad1-EGFP)G42Zjh/J (G42), or FVB-Tg(GadGFP)45704Swn/J (GIN) mice (Jackson) of either sex were made as described previously (Cruikshank et al., 2002) and in accordance with guidelines of the New York University Animal Welfare Committee. Briefly, mice were anesthetized with halothane and decapitated. The brain was placed in cold $\left(0-4^{\circ} \mathrm{C}\right)$ oxygenated artificial CSF (ACSF, in mm: $125 \mathrm{NaCl}, 25 \mathrm{NaHCO}_{3}, 25$ glucose, $2.5 \mathrm{KCl}, 1.25 \mathrm{NaH}_{2} \mathrm{PO}_{4}, 2$ $\mathrm{CaCl}_{2}$, and $1 \mathrm{MgCl}_{2}$ ). Slices (300-500 $\mu \mathrm{m}$ thickness) were cut at a $15^{\circ}$ angle from the horizontal plane with a Leica VT1200S vibrating microtome. Slices were maintained at $37^{\circ}$ for $30 \mathrm{~min}$ and thereafter at room temperature before recording. Recordings were made from slices (1-2 per brain) where the pyramidal cell apical dendritic trunks ran parallel or emerged slightly relative to the cut surface, and where primary auditory cortex (A1; located laterally to the rostral half of the retained part of the hippocampus), the ventral medial geniculate nucleus (MGv), and the thalamocortical fiber tract were present. In a subset of slices, the location of A1 was confirmed by stimulating MGv and locating short-latency intracellular responses in cortical layers 3-4 (Rose and Metherate, 2005).

During recording, slices were perfused with oxygenated $32-34^{\circ} \mathrm{C}$ ACSF. Slices were viewed under infrared differential interference contrast microscopy (Stuart et al., 1993). Layer 4 was provisionally identified under low magnification at $\sim 1 / 3$ of the total cortical depth, and at high magnification ( $40 \times$ objective) by the relatively low density of large pyramidal neurons compared with layers 3 and 5. GFP-expressing cells were identified under epifluorescence. Recording pipettes had a resistance of 5-10 $\mathrm{M} \Omega$ when filled with (in $\mathrm{mM}$ ): $130 \mathrm{~K}$-gluconate, $5 \mathrm{KCl}, 10$ phosphocreatine, 10 HEPES, 4 ATP-Mg, 0.3 GTP, pH 7.3. Stimulation and recording were done with Igor software (Wavemetrics). Voltage responses were recorded using BVC-700A amplifiers (Dagan) and digitized at $8 \mathrm{kHz}$ using an ITC-18 interface (Instrutech). Voltages were corrected for liquid junction potential $(\sim 10 \mathrm{mV})$. Recordings were made in current-clamp mode. Intrinsic membrane properties (Table 1) were recorded on initial break-in by measuring the voltage response to $1 \mathrm{~s}$ incremental current steps. In synaptically connected cells, suprathreshold stimulation evoked unitary excitatory or inhibitory postsynaptic potentials (EPSPs or IPSPs, respectively) in the target cell(s). A bidirectional test was counted as two possible connections, so a nonreciprocal connec- 
A

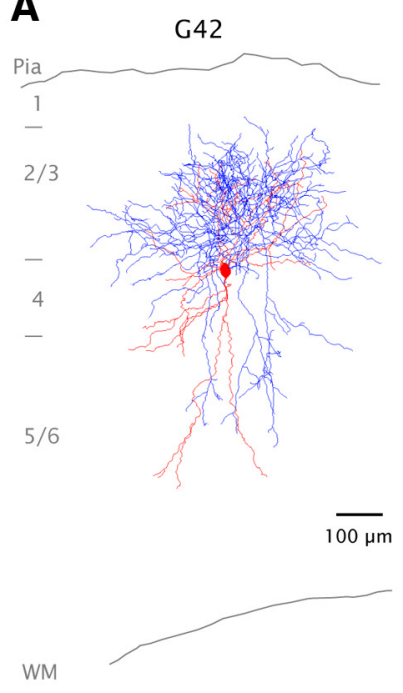

$\mathrm{Bi}$

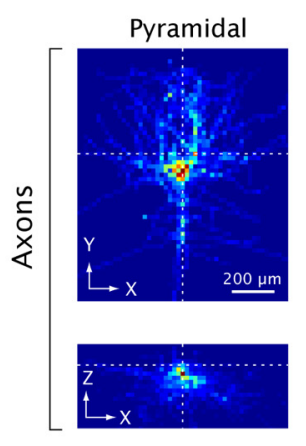

$\mathrm{Bii}$

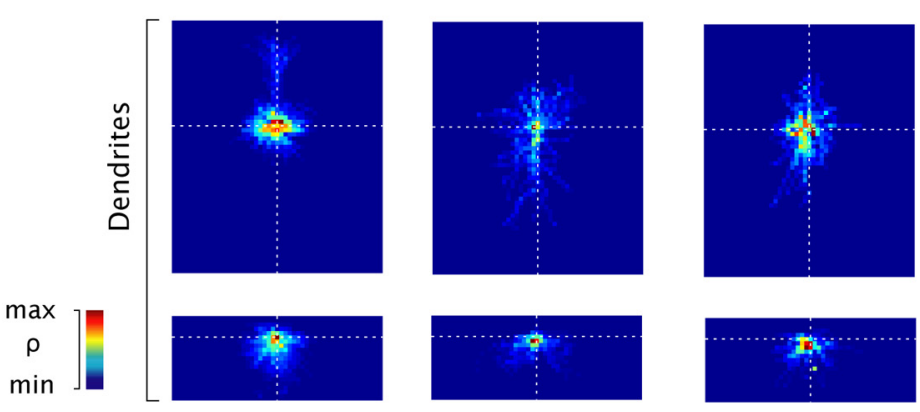

Figure 2. Anatomical reconstruction. $A$, representative G42 (left) and GIN neurons (middle, right). Red, soma and dendrites; blue, axons. Approximate laminar boundaries and outlines of pia and white matter (WM) are indicated. $\boldsymbol{B}$. Average process length density $(\rho)$ maps for all reconstructed cells of each type, with somata aligned (see Materials and Methods, Morphology). $n=7$ cells of each type (axons), $n=5$ (dendrites), except for GIN neurons where $n=5$ (dendrites), $n=3$ (axons). The 3-dimensional process length density maps are projected onto the XY plane (Bi, Bii, top) and the XZ plane (Bi, Bii, bottom). Values are normalized separately for each panel.

In a subset of recordings, presynaptic cells were stimulated in loose cell-attached mode (Barbour and Isope, 2000). Seal resistance during cellattached recording was typically $50-100 \mathrm{M} \Omega$. In this configuration, action potentials (APs) evoked by suprathreshold current pulses were readily apparent in the presynaptic voltage traces. Connections found in loose cell-attached mode were verified by repatching the presynaptic cell in whole-cell mode with a new electrode.

The relative positions of the recorded somata on the lateral (rostrocaudal) and interlaminar (layer 1/layer 6) axes were measured directly from the monitor; measurements were calibrated using a microscope slide with a graticule etched in $10 \mu \mathrm{m}$ increments. After data collection, wholecell recording was re-established with pipettes containing $0.5 \%$ biocytin for $>20 \mathrm{~min}$; slices were fixed immediately and the filled neurons were later visualized using avidin-biotin and 3,3' diaminobenzidine/horseradish peroxidase histochemistry (ABC kit, Vector Laboratories), then mounted on slides in aqueous medium.

Physiology data analysis. Data were analyzed off-line using MATLAB (The MathWorks). Experiments where the resting membrane potential $\left(\mathrm{V}_{\mathrm{m}}\right)$ of either a presynaptic or postsynaptic cell exceeded $-50 \mathrm{mV}$ (where persistent spontaneous firing was observed), or where the access resistance increased substantially $(>30 \%)$ during the course of the experiment, were excluded. Over a given set of trials, resting membrane potential generally did not fluctuate by more than $\pm 2 \mathrm{mV}$. PSP traces that contained spontaneous action potentials or large nonevoked PSPs $(>10 \times$ mean evoked PSP amplitude) were excluded. These typically constituted $<1 \%$ of the dataset. For average PSP traces, individual traces were aligned by triggering to stimulus onset. Triggering to AP onset (in a subset of the data) yielded results that did not differ appreciably from stimulus-triggered averages. Mean PSP amplitudes were measured baseline-to-peak.

To obtain the fitted curves for connection probability $\left(\mathrm{P}_{\mathrm{C}}\right)$ as a function of distance (see Fig. 4), experimental data were grouped into $40 \mu \mathrm{m}$ bins and fitted with a Gaussian function:

$$
P_{C}(d)=A e^{\left(-d^{2} / 2 \sigma^{2}\right)}
$$

where $d$ represents distance, $A$ represents peak probability, and $\sigma$ represents spread of connectivity; fits were done using nonlinear-leastsquares regression. $d$ was the radial distance between somata in the XY plane as defined in Results:

$$
d=\sqrt{x^{2}+y^{2}}
$$

tion would yield a connection rate of 0.5 . Connections were monosynaptic as evidenced by short average latency, monophasic rising component, and small average amplitude. Presynaptic cells were stimulated with 1 or more pulses of $5 \mathrm{~ms}$ each at $5-80 \mathrm{~Hz}$ ( 5 pulses were used in most experiments), followed by an additional pulse after $0.5 \mathrm{~s}$ to assess recovery from short-term synaptic plasticity. During data collection, stimulus trains were separated by $3-6 s$ to permit recovery to baseline conditions. Average responses were compiled from 50 to 100 sweeps. Because resting $\mathrm{V}_{\mathrm{m}}$ was often close to the reversal potential for $\mathrm{Cl}^{-}$ $(\sim-85 \mathrm{mV})$, the postsynaptic cell was kept at $-60 \mathrm{mV}$ by injection of holding current when recording inhibitory responses, and data were collected only after responses reached steady-state levels (generally within 15 min of establishing whole-cell mode).
Morphology. Distance measurements in fixed slices were corrected for average postfixation shrinkage (XY plane: $20 \pm 5 \%$, $z$-axis: $47 \pm 10 \%$; $n=16$ slices). XY shrinkage was determined by biocytin-filling 2 neurons and comparing the intersomatic distance measured from live video (see above, Dissection and recording) to the postfixation distance measured with Neurolucida (MBF Bioscience). Z shrinkage was obtained from the total postfixation slice thickness compared with the original $300 \mu \mathrm{m}$ of the acute prep. Neurons were reconstructed using a $100 \times$ oil-immersion objective and Neurolucida. Average process length density maps (Shepherd et al., 2005; Stepanyants and Chklovskii, 2005; Brown and Hestrin, 2009) for axons and dendrites for each cell type were generated 
A $\quad P \rightarrow P$
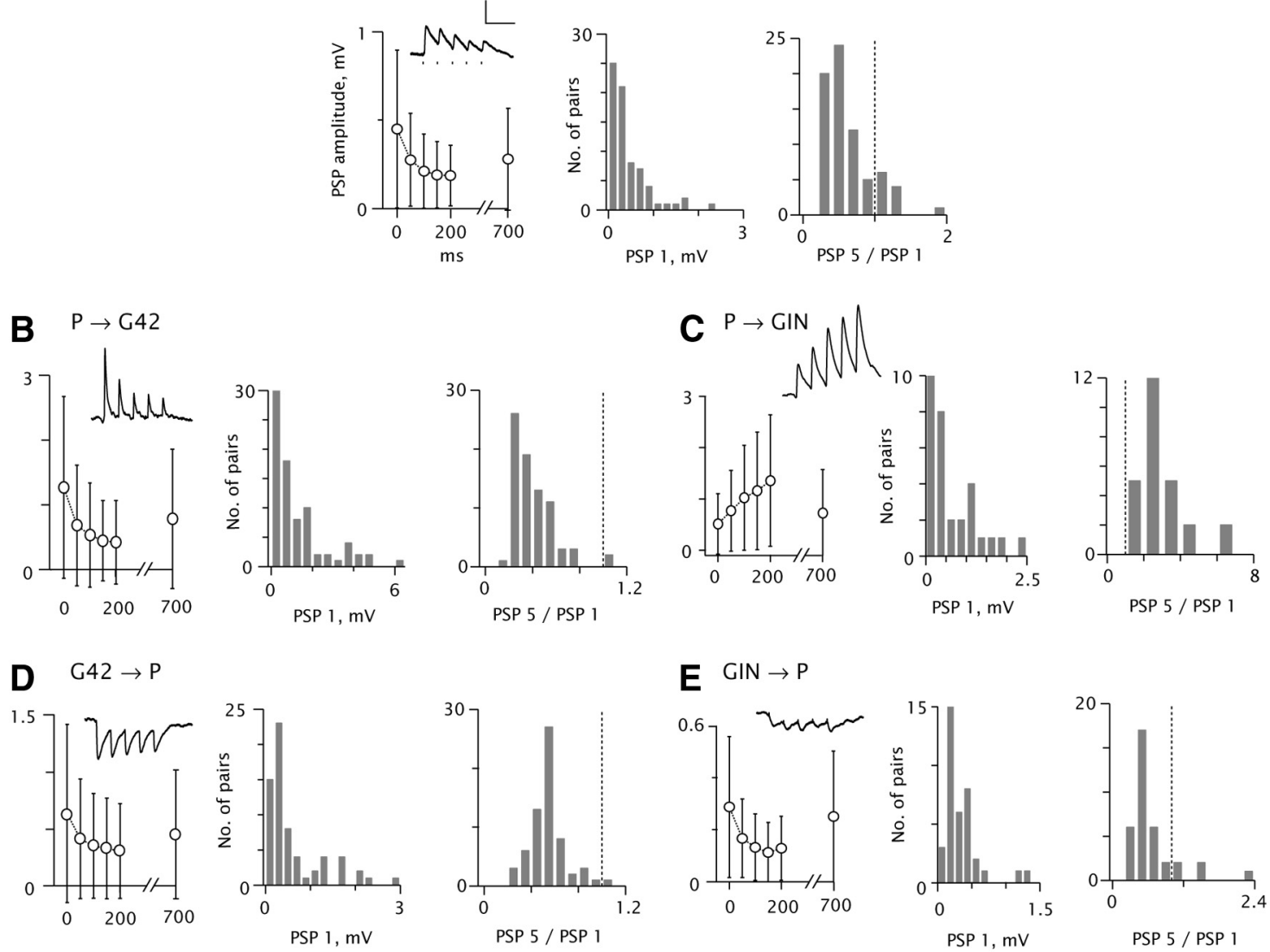

Figure 3. Synapse strength and dynamics. Data are grouped according to presynaptic and postsynaptic cell type, as indicated. $\boldsymbol{A}-\boldsymbol{E}$, Left, pooled data (mean and SD) for mean peak PSP amplitudes, $20 \mathrm{~Hz}$ train and recovery response (note X scale discontinuity). Insets, example postsynaptic voltage traces. Spike times are indicated by tick marks in $A$. Scale: $100 \mathrm{~ms}, 0.5 \mathrm{mV}$. Resting $\mathrm{V}_{\mathrm{m}}=-69 \mathrm{mV}(\boldsymbol{A}),-67(\boldsymbol{B}),-64(\boldsymbol{C}),-66(\boldsymbol{D}),-59(\boldsymbol{E}) . \boldsymbol{A}-\boldsymbol{E}$, Middle, histograms of mean amplitude of the first PSPs. A $7.6 \mathrm{mV}$ EPSP in $\boldsymbol{B}$ is not shown. $\boldsymbol{A}-\boldsymbol{E}$, Right, histograms of the ratio of the amplitude of the last (PSP 5) to the first (PSP 1) response in the $20 \mathrm{~Hz}$ train. Dashed lines denote PSP 5/PSP $1=1 . n=71(\boldsymbol{A}), 80(\boldsymbol{B}), 30(\boldsymbol{C}), 65(\boldsymbol{D}), 37(\boldsymbol{E})$ pairs.

as follows. The soma was assigned the location $\mathrm{X}, \mathrm{Y}, \mathrm{Z}=0$, and the relative location of the beginning and endpoint of each straight segment in the tracing was then obtained in Neurolucida Explorer (segment points analysis; mean segment length was $4.5 \pm 3.5 \mu \mathrm{m}$, axons, $n=$ $86,229$ segments; $3.2 \pm 3.2 \mu \mathrm{m}$, dendrites, $n=34,970)$. The remaining analysis was done in Matlab using custom-written software. Arbor line density ( $\rho$, units of $\mu \mathrm{m}^{-2}$ ) for the three-dimensional space surrounding the soma was derived from the segment point data (see Equation 1 in Stepanyants et al., 2005) and binned into voxels of $20 \times 20 \times 20 \mu \mathrm{m}$. This process was repeated for each reconstructed cell of each type, and the results were averaged to yield the three-dimensional process length density maps shown in Figure $2 B$. Axonal/dendritic overlap $\omega$ as a function of intersomatic distance $(\lambda, \mu)$ in the X-Y plane was then calculated via the cross-correlation:

$$
\omega(\lambda, \mu)=\sum_{x=-X}^{X} \sum_{y=-Y}^{Y} \sum_{z=-Z}^{Z} \rho_{a x}(x, y, z) \rho_{d e n}(x+\lambda, y+\mu, z)
$$

$z$-axis intersomatic distance was held at zero because the recorded cells were all at approximately the same depth relative to the cut surface $(36 \pm 16$ $\mu \mathrm{m} ; n=26$ ). Equation 3 yields a two-dimensional cross-correlogram (see Fig. $5 A$ ), where each pixel represents the total predicted axonal/dendritic overlap for a postsynaptic cell with soma located at the given X-Y distance relative to the presynaptic soma. To calculate the predicted overlap as a function of radial distance (see Fig. $5 B$ ) the value of $\omega$ for each pixel in the cross-correlogram was binned according to its Euclidean distance from $\mathrm{X}$, $\mathrm{Y}=0$ (bin size $40 \mu \mathrm{m}$ ), and data were averaged within each bin.

To estimate the fraction of synaptic contacts kept intact by slicing, a corrected 3-dimensional process length density map $\hat{\rho}(x, y, z)$ was created for each cell type by taking the better-preserved half (i.e., deep to the
Table 2. Synapse amplitude and short-term dynamics

\begin{tabular}{|c|c|c|c|c|c|c|c|c|c|c|}
\hline & \multicolumn{2}{|c|}{$\begin{array}{l}\mathrm{P} \rightarrow \mathrm{P}, \\
n=76\end{array}$} & \multicolumn{2}{|c|}{$\begin{array}{l}\mathrm{P} \rightarrow \mathrm{G} 42, \\
n=78\end{array}$} & \multicolumn{2}{|c|}{$\begin{array}{l}\mathrm{P} \rightarrow \mathrm{GIN}, \\
n=30\end{array}$} & \multicolumn{2}{|c|}{$\begin{array}{l}G 42 \rightarrow P, \\
n=65\end{array}$} & \multicolumn{2}{|c|}{$\begin{array}{l}\mathrm{GIN} \rightarrow \mathrm{P}, \\
n=37\end{array}$} \\
\hline & Mean & SD & Mean & SD & Mean & SD & Mean & SD & Mean & SD \\
\hline & 0 & 0.4 & 1.29 & 1.40 & 0.5 & 0.5 & 0.64 & 0.78 & 0.2 & 0. \\
\hline$P$ P & 0.27 & 0.2 & 0.70 & 0.93 & 0 & 0.79 & 0.41 & 0.53 & 0.17 & 0.1 \\
\hline P3 & 0.21 & 0.2 & 0.56 & 0.80 & 1. & 02 & 0.35 & 0.46 & 0. & 0.1 \\
\hline P4 & 0.19 & 0.19 & 0.47 & 0.62 & 1.16 & 1.14 & 0.33 & 0.44 & 0.11 & 0.12 \\
\hline P5 & 0.18 & 0.17 & 0.44 & 0.64 & 1.36 & 1.28 & 0.31 & 0.42 & 0.13 & 0.12 \\
\hline$P(r$ & 0.28 & 0.29 & 0.80 & 1.07 & 0.73 & 0.84 & 0.45 & 0.57 & 0.25 & 0.25 \\
\hline SP 5/PSP 1 & 0.51 & 0.36 & 0.38 & 0.38 & 2.89 & 1.36 & 0.52 & 0.23 & 0.604 & 0.51 \\
\hline
\end{tabular}

Values represent average amplitudes (baseline to peak) of successive PSPs in $20 \mathrm{~Hz}$ evoked trains, and recovery response (compare Fig. 3 , left of each panel).

cut surface; $Z<0)$ and reflecting it around the XY plane at the level of the soma $(Z=0)$. The reflected intact axonal and dendritic density maps were used to generate $\hat{\omega}(\lambda, \mu)$, the corrected predicted overlap, using equation 3. The estimated intact fraction is then the average value of $\omega / \hat{\omega}$ for each cell/process type.

Statistics. Data are reported as mean $\pm \mathrm{SD}$ except as noted. For comparisons of connection probability between datasets, significance was determined via $\chi^{2}$ tests; for continuous-valued data, two-tailed, unpaired $t$ tests were used.

\section{Results}

Physiological and anatomical characterization of neurons Whole-cell current-clamp recordings were made from neurons in slices aged 19-32 postnatal days, when hearing properties (Eh- 

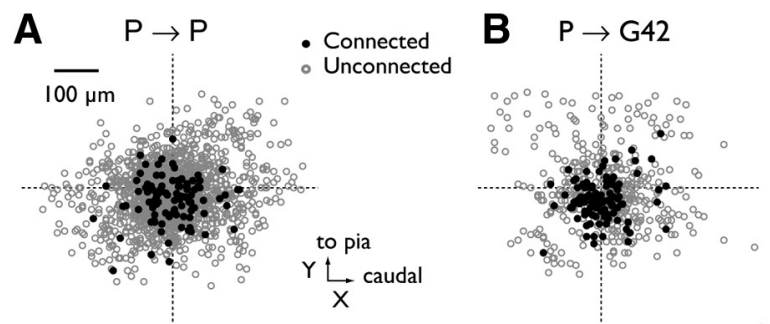

$$
\text { C } \quad P \rightarrow G I N
$$
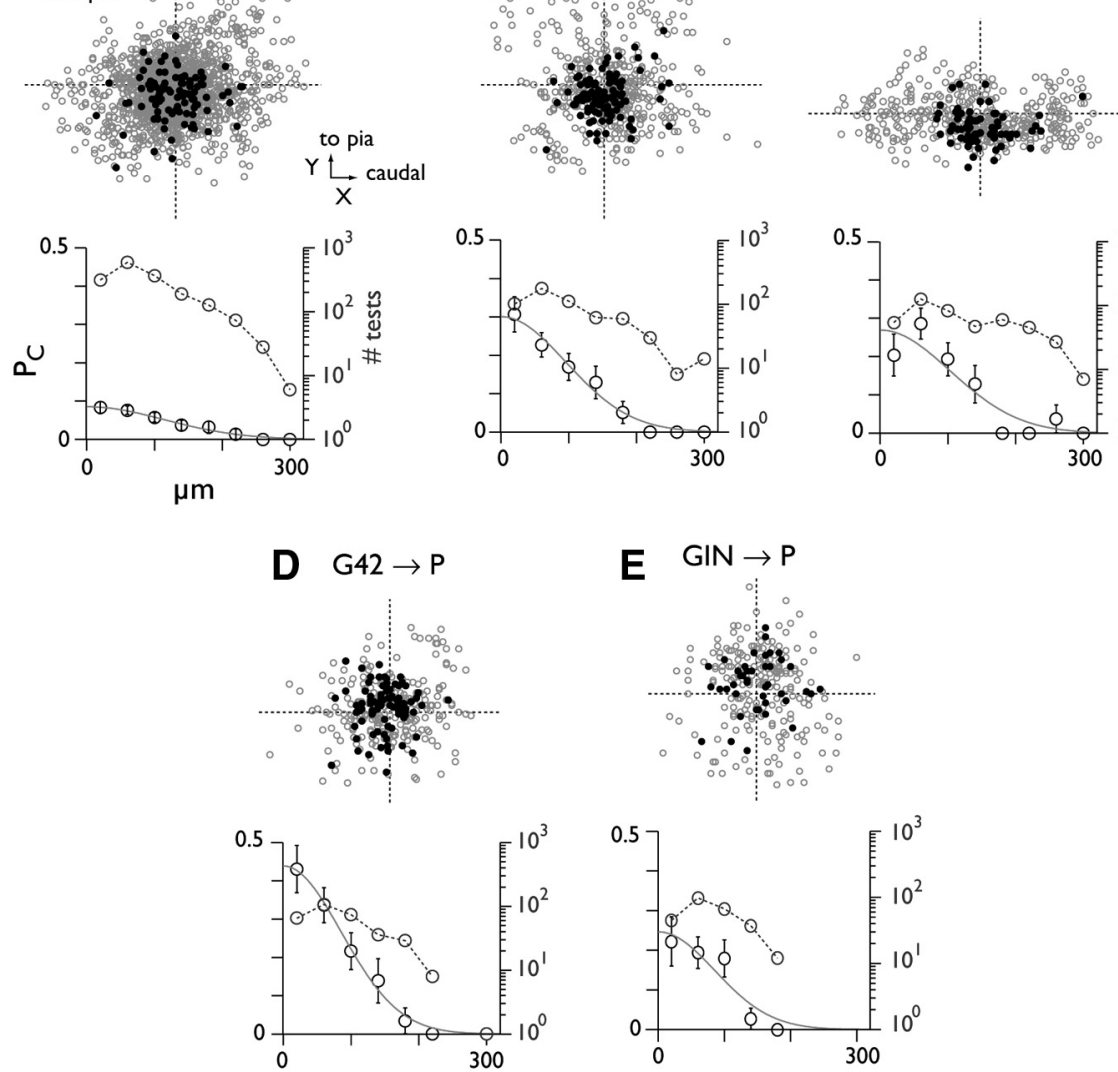

Figure 4. Synaptic $P_{C}$ versus intersomatic distance. $A$, Data for pyramid-pyramid pairs. Top, scatter plot showing location of unconnected (gray) and connected (black) postsynaptic somata relative to the presynaptically tested cell (intersection of dashed lines). Bottom, connection probability (mean \pm SEM; circles with error bars) versus radial distance between somata. Data are divided into $40 \mu \mathrm{m}$ bins. Curves are Gaussian fits to the data. Circles with dashed line denote the number of tests at each distance (right-hand axis; note log scale). $\boldsymbol{B}-\boldsymbol{E}$, Data for pyramid-interneuron connections.

Table 3. Parameter values for Gaussian fits to physiologically measured and anatomically predicted connectivity profiles

\begin{tabular}{|c|c|c|c|c|c|}
\hline & $\mathrm{P} \rightarrow \mathrm{P}$ & $\mathrm{P} \rightarrow \mathrm{G} 42$ & $\mathrm{P} \rightarrow \mathrm{GIN}$ & $\mathrm{G} 42 \rightarrow \mathrm{P}$ & $\mathrm{GIN} \rightarrow \mathrm{P}$ \\
\hline \multicolumn{6}{|l|}{ Physiol. measured } \\
\hline Peak $P_{C}$ & 0.09 & 0.30 & 0.27 & 0.44 & 0.25 \\
\hline Peak $P_{C}$ (normalized) & 1 & 3.3 & 3.0 & 4.9 & 2.9 \\
\hline$\sigma, \mu \mathrm{m}$ & 114 & 92 & 103 & 95 & 85 \\
\hline \multicolumn{6}{|l|}{ Anat. predicted } \\
\hline Peak $P_{C}$ (normalized) & 1 & 0.7 & 0.8 & 4.7 & 4.5 \\
\hline$\sigma, \mu \mathrm{m}$ & 96 & 91 & 90 & 63 & 63 \\
\hline
\end{tabular}

Parameter values for Gaussian fits (see Materials and Methods, Eq. 1) to measured $\mathrm{P}_{\mathrm{c}}$ profiles (Physiol., top) and profiles derived from anatomical overlap (Anat., bottom). Normalized values for peak $P_{C}$ in each case are relative to the value for $\mathrm{P} \rightarrow \mathrm{P}$ connectivity. $\sigma$ represents radial spread in $\mu \mathrm{m}$.

ret, 1976; Song et al., 2006) and A1 neuronal intrinsic properties (Metherate and Aramakis, 1999; Oswald and Reyes, 2008, 2011) have reached maturity. Recordings were made from deep layer $2 / 3$ and layer 4 (Fig. $1 A$ ), corresponding to a major thalamorecipient region of A1 (Müller-Preuss and Mitzdorf, 1984; Huang and Winer, 2000; Cruikshank et al., 2002). Presumptive excitatory cells were identified by their pyramidal somata, and consistently produced EPSPs in their postsynaptic targets (see below, Synapse strength and short-term dynamics). Inhibitory cell firing properties ranged widely (Fig. $1 B, C$ ). To identify specific classes of interneurons, recordings were made using transgenic mouse strains that express GFP selectively in parvalbumin-positive fast- spiking (FS) cells (G42; Chattopadhyaya et al., 2004) or in somatostatin-positive, non-FS cells (GIN; Oliva et al., 2000; Ma et al., 2006; McGarry et al., 2010). For simplicity, we use "G42" and "GIN" to denote fluorescent cells in the respective lines hereafter, except as noted.

G42 cells (Fig. $1 \mathrm{Bi}, \mathrm{C}$, filled red circles) displayed relatively narrow AP widths and little spike rate adaptation. GIN cells (Fig. $1 C$, blue circles) displayed a range of firing patterns (Fig. 1Bii), but were generally distinct from G42 cells in their intrinsic membrane properties (Table 1), e.g., displaying broader action potentials (Fig. $1 C$, abscissa) and greater spike rate adaptation (prolongation of interspike intervals with sustained input; Fig. 1C, ordinate). A subset of GIN cells fired one or more rebound spikes after hyperpolarization (examples, Fig. $1 B i i b, d)$ and were designated lowthreshold spiking (LTS; Goldberg et al., 2004; Otsuka and Kawaguchi, 2009; see caveats therein).

Because the G42 and GIN lines combined do not label all cortical interneurons (Ma et al., 2006; Rudy et al., 2011), we also recorded from a random sample of inhibitory cells in WT mice. These were classified as FS or non-FS based on AP width and degree of spike rate adaptation, as shown in Figure $1 C$. As expected, the intrinsic properties of G42 cells were comparable to those of WT FS cells (Table 1). GIN cell intrinsic properties overlapped those of WT non-FS cells (Fig. $1 C$, blue vs open circles; Table 1 ) although they were statistically distinguishable in several respects (Table 1), notably resting $\mathrm{V}_{\mathrm{m}}$, input resistance, threshold voltage, and afterhyperpolarization time. LTS cells were less common in the WT (6/57) than the GIN population (14/46).

To study the anatomy of the different cell classes, recorded cells were biocytin-filled and subsequently visualized (see Materials and Methods, Dissection and recording). G42 cells were consistently (33/33) the basket cell type, with round or ovoid somata and processes extending radially in the surrounding tissue (example, Fig. 2 A, left; Marin-Padilla, 1969; Chattopadhyaya et al., 2004). The majority of GIN cells (10/17) were the Martinotti type (Kawaguchi and Kubota, 1997; Wang et al., 2004; Ma et al., 2006) based on the presence of one or more low-order axons projecting directly to layer 1 and ramifying extensively there (Fig. $2 \mathrm{~A}$, middle); $7 / 17$ were basket-like or unclassified (Fig. $2 \mathrm{~A}$, right); of these, 4 had truncated ascending low-order axons suggesting that they may have been Martinotti cells. The high fraction of Martinotti cells in the GIN population is in agreement with other reports (Oliva et al., 2000; Ma et al., 2006; McGarry et al., 2010; Rudy et al., 2011).

A representative subset of biocytin-filled cells of each class was reconstructed in detail (examples, Fig. $2 \mathrm{~A}$ ). To allow quantitative study of the anatomy (see below, Figs. 5-7), 3-dimensional maps of the arborizations of each cell type were obtained by dividing the tissue into a rectilinear grid of $20 \times 20 \times 20 \mu \mathrm{m}$ voxels. Hereafter, $\mathrm{X}$ denotes the rostrocaudal axis; $\mathrm{Y}$ denotes the axis 
running from the pia to the white matter, and $\mathrm{Z}$ denotes depth relative to the cut surface. Somata were aligned at X, Y, Z = 0 and the total length of axons/dendrites contained in each voxel was calculated (Stepanyants and Chklovskii, 2005; cf. Shepherd et al., 2005; Brown and Hestrin, 2009) to yield maps of average process length density (see Materials and Methods, Morphology). Patterns of arborization in the XY plane varied by cell type (Fig. $2 B$, top). As expected, P-cell axons were sparse and extended relatively far while those in G42 and GIN cells arborized densely; GIN cells on average showed a more vertical (i.e., $y$-axis) distribution of axons than G42 cells (Fig. 2A, left vs middle; $2 \mathrm{Bi}$, middle vs right; $\mathrm{cf}$. Kawaguchi and Kubota, 1993; Xiang et al., 1998), with discrete apical arborization (Fig. $2 \mathrm{Bi}$, right; compare Fig. $2 \mathrm{~A}$, middle).

\section{Synapse strength and} short-term dynamics

Synaptic connections were identified by recording simultaneously from up to four cells, and evoking action potentials in each cell successively while monitoring the responses of the others. EPSPs evoked between pyramidal cells $(\mathrm{P} \rightarrow \mathrm{P}$; Fig. $3 A$ ) had peak amplitudes of $0.45 \pm 0.45 \mathrm{mV}$ on average for the first response in an evoked train (Fig. 3A, left, middle, summarized in Table 2). Subsequent responses evoked at 20 $\mathrm{Hz}$ typically depressed (EPSP $5<$ EPSP 1 in $64 / 76$ pairs; Fig. $3 A$, right). Trains evoked at 5-40 Hz were qualitatively similar, although depression was more pronounced at higher frequencies (data not shown). $\mathrm{P} \rightarrow \mathrm{G} 42$ connections (Fig. $3 B$ ) had a mean amplitude of $1.29 \pm 1.40 \mathrm{mV}(p<0.0001$, $\mathrm{P} \rightarrow \mathrm{G} 42$ vs $\mathrm{P} \rightarrow \mathrm{P}$ unpaired $t$ test), and also showed pronounced depression.

Initial evoked $\mathrm{P} \rightarrow \mathrm{GIN}$ EPSPs (Fig. 3C) were $0.51 \pm 0.59 \mathrm{mV}$ on average. $\mathrm{P} \rightarrow$ GIN EPSPs were consistently facilitating (30/30 pairs; Fig. 3C, right; Markram et al., 1998; Reyes et al., 1998; Thomson et al., 1993). Initial G42 $\rightarrow$ P IPSPs were $0.64 \pm 0.78 \mathrm{mV}$, compared with $0.29 \pm 0.27 \mathrm{mV}$ for $\mathrm{GIN} \rightarrow \mathrm{P}$ IPSPs (Fig. $3 D, E$, left, middle). Sixty-three of sixty-five $\mathrm{G} 42 \rightarrow \mathrm{P}$ and $33 / 37 \mathrm{GIN} \rightarrow \mathrm{P}$ trains depressed at $20 \mathrm{~Hz}$ (Fig. $3 D, E$, right); however, the $\mathrm{GIN} \rightarrow \mathrm{P}$ response envelopes typically showed some summation (Fig. $3 E$, left, inset; cf. Beierlein et al., 2003).

\section{Spatial profiles of connectivity}

Cells whose somata were close together had a higher probability of being connected than those that were far apart, at least within the range we examined (several hundreds of $\mu \mathrm{m}$ ). The relative spatial profiles of excitatory and inhibitory connectivity are likely to be important in vivo, because together they determine the spread of local excitation, and thus may influence cortical receptive field properties such as frequency tuning and spectral inte-
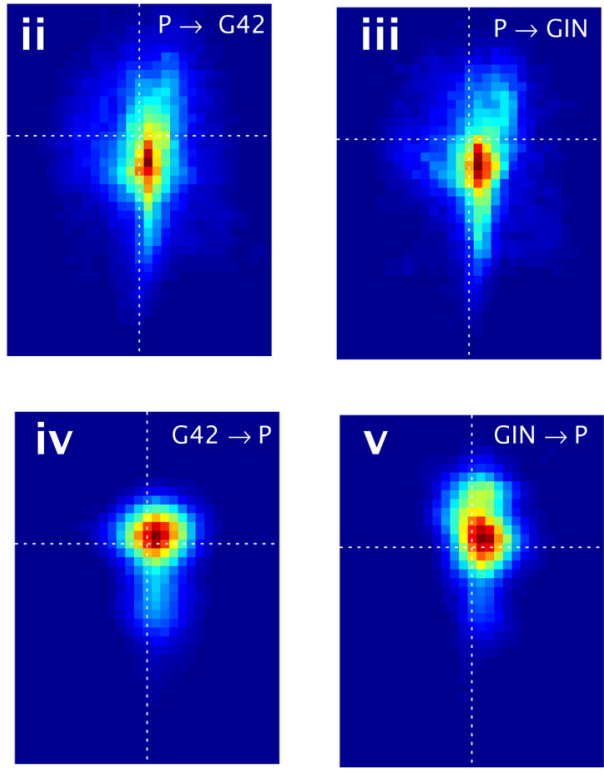

\section{$\mathbf{B i}$}

ii

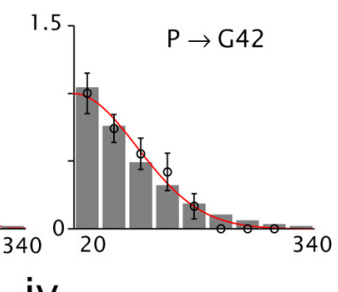

iv

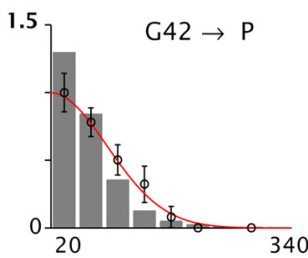

iii

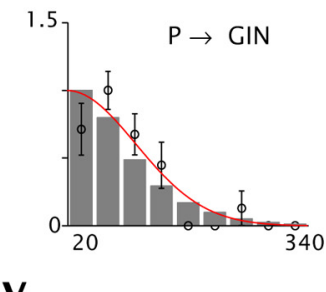

\section{V}

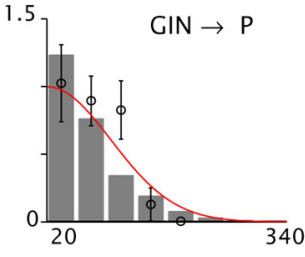

Figure 5. Connection profiles predicted by morphology; comparison to physiology data. $\boldsymbol{A} \boldsymbol{i}-\boldsymbol{A} \boldsymbol{v}$, total overlap between presynaptic axons and postsynaptic dendrites (color scale, normalized to peak value for each panel) versus intersomatic distance $(X, Y)$ axes, derived from the cross-correlation of 3-D axonal and dendritic length density maps (Fig. $2 B$; see Materials and Methods, orphology). Dashed lines denote intersomatic distance $=0 . \mathbf{B} \mathbf{i}-\mathbf{B v}$, axonal/dendritic overlap as a function of radial distance between somata (gray bars), scaled for best fit to normalized measured $P_{C}$ profiles (circles with error bars; compare Fig. 4); Gaussian fits to $P_{C}$ profiles are superimposed (red).

Table 4. Effect of slicing on cell intactness

\begin{tabular}{|c|c|c|c|c|c|c|c|c|c|}
\hline & & & & Total f & tion in & & & & \\
\hline & Soma & $\mathrm{l}, \mu \mathrm{m}$ & & Axons & & & Dendr & & \\
\hline & Mean & SD & $n$ & Mean & SD & $n$ & Mean & SD & $n$ \\
\hline$P$ & 46.3 & 16.8 & 7 & 0.57 & 0.07 & 5 & 0.70 & 0.12 & 7 \\
\hline G42 & 48.3 & 26.3 & 7 & 0.60 & 0.08 & 4 & 0.71 & 0.18 & 7 \\
\hline GIN & 37.6 & 12.2 & 5 & 0.60 & 0.11 & 3 & 0.65 & 0.10 & 5 \\
\hline
\end{tabular}

Soma depth is relative to the cut surface. $n$ denotes number of reconstructed cells for each category. Differences between cell types were not significant ( $p>0.05$, ANOVA).

gration (Schreiner et al., 2000; Oswald et al., 2006). To examine the distance dependence systematically, we recorded the locations of connected and unconnected target neurons relative to the presynaptically tested cell, in the XY plane (Fig. 4, top of each panel). We then binned the data according to radial distance (d), and divided the number of connections by the number of tests to 

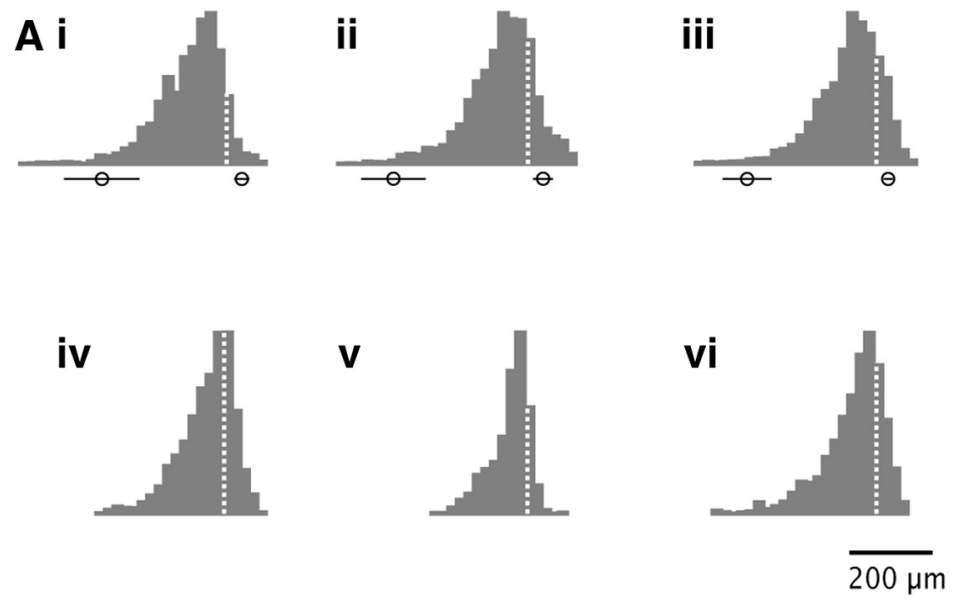

B

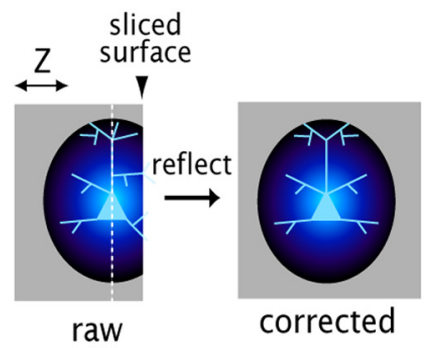

C i

$$
\mathrm{P} \rightarrow \mathrm{P}
$$
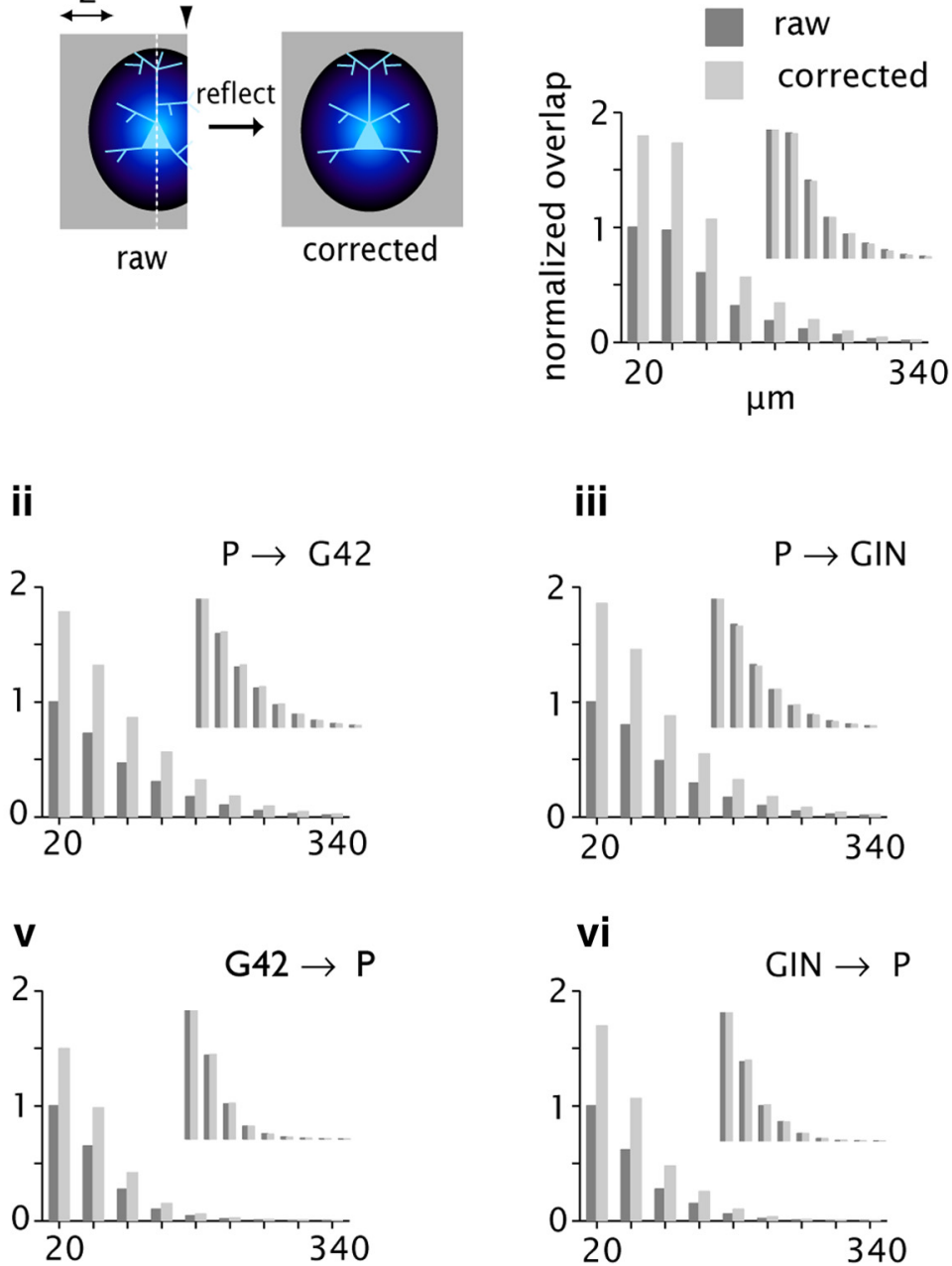

\section{iii}
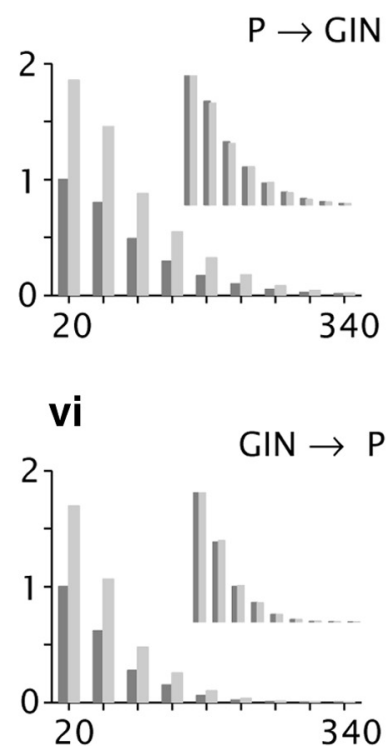

Figure 6. Effect of slicing on connectivity profiles. Ai-Avi, Normalized histograms of process length density on the $z$-axis (orthogonal to the cut surface). Data are derived from the density maps in Figure $2 B$. Dashed lines at $X=0$ denote location of the soma. Circles with bars denote the mean and SD of the location of the deep (left) and superficial (right) cut surfaces. $B$, Schematic diagram of the correction procedure. Blue ovoid denotes the 3-D process length density map, projected here onto the YZ plane. The map is truncated at the cut surface (arrowhead) in the raw data, left. White dashed line denotes XY plane passing through the soma (pale blue). Reflecting around this plane produces the corrected map, right. Ci-Cvi, axonal/dendritic overlap (left axis) versus radial distance (bottom axis) for the raw data corrected (dark gray bars) compared with the corrected (light gray). Scale is normalized to the peak value for the raw data in each panel. Insets, same data with separate normalization for raw and corrected, respectively.

obtain $\mathrm{P}_{\mathrm{C}}$ spatial profiles (Fig. 4, bottom of each panel). $\mathrm{P}_{\mathrm{C}}$ (black circles) decreased progressively with distance for all connection types, falling to zero when the somata were $240 \mu \mathrm{m}$ or more apart. The $\mathrm{P}_{\mathrm{C}}$ profiles were parameterized according to maximum $\mathrm{P}_{\mathrm{C}}$ and spatial spread by fitting each $\mathrm{P}_{\mathrm{C}}$ profile with a Gaussian function (Fig. 4, bottom; Table 3). $\mathrm{P} \rightarrow \mathrm{P}$ connectivity was relatively low, even at the limit of zero intersomatic distance (Fig. $4 A$, bottom; peak $\mathrm{P}_{\mathrm{C}}=0.085$ ), while peak $\mathrm{P}_{\mathrm{C}}$ between pyramids and both interneuron classes was substantially higher (Fig. $4 B-E$ ). Overall $\mathrm{P} \rightarrow \mathrm{P}$ connectivity (all distances: $\mathrm{P}_{\mathrm{C}}=0.062 ; 108$ connections in 1736 tests) was significantly lower $(p<$ $0.0001)$ than $\mathrm{P} \rightarrow \mathrm{G} 42(0.18 ; 102 / 563$; Fig. $4 C)$ and $\mathrm{P} \rightarrow \mathrm{GIN}$ (0.16; 70/449; Fig. 4C). Among inhibitory connections, the $\mathrm{G} 42 \rightarrow \mathrm{P}$ rate was modestly but significantly higher $(0.27 ; 86 / 321)$ than $\mathrm{GIN} \rightarrow \mathrm{P}$ $(0.16 ; 42 / 259 ; p<0.005)$. The lateral spread of connectivity ( $\sigma$; see Materials and Methods, Eq. 1) ranged from $85 \mu \mathrm{m}$ $(\mathrm{GIN} \rightarrow \mathrm{P})$ to $114 \mu \mathrm{m}(\mathrm{P} \rightarrow \mathrm{P})$. Thus, the spread of connectivity was qualitatively similar for all cell types.

In contrast to the strong distance dependence of connection probability, average PSP strength among connected cells was not significantly correlated with radial distance between somata $(0.2<\mathrm{r}<$ $0.2 ; p>0.15)$ for any connection type (data not shown).

\section{Connectivity profiles predicted by morphometry; comparison to measured $\mathrm{P}_{\mathrm{C}}$ profiles}

Geometric analysis of axodendritic overlap has been proposed as a tool for predicting local synaptic connectivity (Hellwig, 2000; Kalisman et al., 2003; Shepherd et al., 2005; Stepanyants and Chklovskii, 2005). This method has been applied conservatively, for example, in studying connectivity among different classes of pyramidal cells (Brown and Hestrin, 2009), but it is unclear how closely the results could be expected to match measured connectivity among different cell types, due to anatomical variables such as the presence of dendritic spines or differential targeting of proximal versus distal dendritic sites. To compare predictions based on our anatomical data (Fig. 2) to the physiologically measured connectivity profiles (Fig. 4), we generated two-dimensional maps of predicted connectivity in the $\mathrm{XY}$ plane via the cross-correlation of presynaptic axonal and postsynaptic dendritic process length density maps for the various cell types (see Materials and Methods, Morphology). Essentially, the three-dimensional maps were slid relative 
to each other in the XY plane (representing the distance between somata); at each position, the superimposed axonal and dendritic density values were multiplied pointfor-point, and then summed. This procedure yields a two-dimensional map of predicted overlap as a function of the distance between somata (Fig. $5 \mathrm{~A}$; see Materials and Methods, Morphology.).

To compare the axonal/dendritic overlap to the physiologically measured $\mathrm{P}_{\mathrm{C}}$ values as a function of intersomatic distance, predicted overlap versus radial distance was calculated in $40 \mu \mathrm{m}$ bins, similar to the derivation of $\mathrm{P}_{\mathrm{C}}$ profiles (Fig. 4; see Materials and Methods, Physiology data analysis). Hereafter we use "measured" to denote the physiology data and "predicted" to denote values derived from the anatomical reconstructions. When the anatomically predicted connectivity profiles were normalized for each connection type to obtain the best fit to the measured $\mathrm{P}_{\mathrm{C}}$ (Fig. $5 B$, bottom, compare gray bars to open circles), the measured and predicted values did not differ statistically for any class $(p>0.05$, $\chi^{2}$ goodness-of-fit tests), indicating that the spatial spread and overall shape of the connectivity profiles derived by both methods were comparable.

To make a parametric comparison, we fit each overlap profile with a Gaussian function (Table 3, bottom) as was done for the measured $\mathrm{P}_{C}$ profiles (Table 3 , top; Fig. 4), yielding peak anatomically predicted $\mathrm{P}_{\mathrm{C}}$ (dimensionless) and spatial spread $(\sigma$, in $\mu \mathrm{m})$. $\sigma$ for the anatomical predictions was slightly less than $\sigma$ for measured $\mathrm{P}_{\mathrm{C}}$ in all cases, but the variations among connection types were comparable across the two methods, e.g., $\sigma$ was broader for $\mathrm{P} \rightarrow \mathrm{P}$ and narrower for $\mathrm{P} \rightarrow \mathrm{GIN}$. In contrast, the peak connectivity values showed divergent trends. For example, physiologically measured peak $\mathrm{P}_{\mathrm{C}}$ for $\mathrm{P} \rightarrow \mathrm{G} 42$ (3.3; normalized to $\mathrm{P} \rightarrow \mathrm{P}$ ) and $\mathrm{P} \rightarrow \mathrm{GIN}$ (3.0) were both substantially greater than $\mathrm{P} \rightarrow \mathrm{P}(1)$, while the overlap values were modestly lower for $\mathrm{P} \rightarrow \mathrm{G} 42(0.7)$ and $\mathrm{P} \rightarrow \mathrm{GIN}(0.8)$. Normalized peak overlap values for the inhibitory connection types $\mathrm{G} 42 \rightarrow \mathrm{P}(4.7)$ and $\mathrm{GIN} \rightarrow \mathrm{P}(4.5)$ were several-fold higher than for excitatory connections, due mainly to the profuse local axonal branching of both G42 and GIN compared with the relatively sparse arbors of $\mathrm{P}$ cells. These values were qualitatively similar to the normalized measured $\mathrm{P}_{\mathrm{C}}$ values (4.9 and 2.9, respectively). To summarize, the anatomical overlap yielded a good prediction of the spatial profiles but not the relative magnitudes of connectivity among the different cell types. These results were not a byproduct of the slicing process because, as described in the next section, the fraction and spatial extent of axons and dendrites preserved after slicing was consistent across cell types (Table 4; Fig. 6).

\section{Correction for truncation due to slicing}

Recorded cell somata were usually within $\sim 50 \mu \mathrm{m}$ of the cut surface of the $300 \mu \mathrm{m}$ slice (Table 4). A fraction of each cell type's arbor was lost due to slicing, as evidenced by the fact that histograms of axonal and dendritic process density maps were lopsided relative to the soma when viewed orthogonally to the cut surface (Fig. $6 \mathrm{~A}$, note asymmetry around the dashed lines; compare Fig. $2 B i, B i i$, bottom). The asymmetry most likely reflected slicing artifacts rather than the actual anatomy, because neuronal radiations in intact $\mathrm{A} 1$ are axially symmetric when viewed in tangential section (Colonnier, 1964; cf. Wong, 1967). Processes extending deep to the soma were well preserved, however (Fig. $6 \mathrm{~A}$; note that the left side of each histogram tails off gradually within the thickness of the slice). To estimate the effect of slicing on the connectivity rate, we did a set of analyses in which the process length density maps were corrected by taking the fully retained half of each reconstruction and reflecting it in the plane of the soma (schematized in Fig. 6 B). Values of predicted overlap derived from the corrected maps were considerably greater than the corresponding values from the raw data (Fig. 6C, compare light to dark bars), reflecting the loss of processes due to slicing (Table 4). When the raw and corrected values were normalized separately, however, the profiles of predicted connectivity matched each other closely (Fig. $6 \mathrm{C}$, inset graphs). In other words, slicing reduced the magnitude but did not distort the spatial profiles of connectivity. Therefore, the effect of slicing could be compensated by multiplying the Gaussian fits to the measured $\mathrm{P}_{\mathrm{C}}$ data (Fig. 4) by scalar values corresponding to the ratio of corrected to raw process overlap. The resulting estimates of peak connectivity ranged from $0.15(\mathrm{P} \rightarrow \mathrm{P}$, Fig. $7 A$, dashed line) to $0.66(\mathrm{G} 42 \rightarrow$ P, Fig. $7 D)$.

\section{Discussion}

We analyzed the spatial patterns of local synaptic connectivity in the thalamorecipient layer of mouse A1. Connection probability was distance-dependent, dropping to nearly zero when somata were several hundred $\mu \mathrm{m}$ apart. The spread of recurrent excitation among pyramidal cells was comparable to the spread of P-interneuron connectivity. Spatial spread predicted morphometrically via axonal/dendritic overlap did not differ statistically from the physiologically measured values, but the relative peak connectivity rates among the different cell classes predicted by overlap differed considerably from the physiology data. The morphometry also suggested that slicing reduced the overall connectivity but did not distort spatial profiles.

\section{Spatial profiles of synaptic connectivity}

Peak $\mathrm{P}_{\mathrm{C}}$ ranged from 0.09 ( 0.15 corrected for slicing) for $\mathrm{P} \rightarrow \mathrm{P}$, to $0.44(0.66)$ for $\mathrm{G} 42 \rightarrow \mathrm{P}$, and $\mathrm{P}_{\mathrm{C}}$ declined progressively with dis- 
tance (Figs. 4, 7). The relatively sparse and distance-dependent connectivity agrees with most pair recording data from other layers (Oswald et al., 2009) and sensory regions (Holmgren et al., 2003; Perin et al., 2011).

In contrast to our findings, two recent studies using both twophoton glutamate uncaging and dual intracellular recording reported local inhibitory connection probability approaching 1.0 in the superficial layers of mouse frontal (Fino and Yuste, 2011; Packer and Yuste, 2011) and somatosensory cortex (Packer and Yuste, 2011). Slicing-related artifacts probably do not account for the discrepancy between the latter studies and our own; the thickness of the slices was comparable (350 and $300 \mu \mathrm{m}$, respectively), and our corrected estimates for the upper boundaries of peak connectivity before slicing were still relatively low ( 0.66 for $\mathrm{G} 42 \rightarrow \mathrm{P}$ and 0.42 for GIN $\rightarrow$ P; Fig. $7 D, E)$. Differences in sensitivity of the recording technique (voltage clamp in the latter studies, current clamp in ours) are unlikely to account for the difference, because voltage-clamp recordings in layers $2 / 3$ of comparably aged gerbil auditory cortex found a connection probability of only 0.3 for LTS $\rightarrow$ P pairs within $100 \mu \mathrm{m}$ (Takesian et al., 2010). Connection probabilities could be lower in A1 than elsewhere, reflecting the apparent sparseness of coding in A1 (Hromádka et al., 2008). The density of connectivity across different cortical regions remains open to discussion.

\section{Predictions based on axonal/dendritic overlap; comparison to} physiologically measured $\mathrm{P}_{\mathrm{C}}$ profile

Spatial spreads of connectivity predicted by axonal/dendritic overlap were similar to the physiologically measured profiles (Fig. 5B; Table 3, $\sigma$ values). This is noteworthy given that the morphometric analysis omitted several features of the anatomy. For example, FS basket cell axon terminals target somata and proximal dendrites (Marin-Padilla, 1969; Williams et al., 1992; Halasy et al., 1996), while non-FS cell axons preferentially target distal dendrites and axon initial segments (Kawaguchi and Kubota, 1997; Gupta et al., 2000). By not accounting for preferential targeting of proximal areas by FS cells, the morphometry might overestimate the spread of G42 $\rightarrow$ P connectivity. Instead, the predicted $\mathrm{P}_{\mathrm{C}}$ profile for $\mathrm{G} 42 \rightarrow \mathrm{P}$ was narrower than the physiologically measured profile (Fig. 5Biv; Table 3), comparable to the results for other connection types. Additionally, we did not include dendritic spines in the analysis; it is difficult to predict how this factor would influence connectivity profiles.

In contrast, the magnitude of connectivity predicted anatomically diverged from the physiological data (peak $\mathrm{P}_{\mathrm{C}}$, Table 3 ), e.g., in the relative overestimate of $\mathrm{P} \rightarrow \mathrm{P}$ versus $\mathrm{P} \rightarrow$ interneuron connectivity. This is not surprising given that even among a single class (layer $5 \mathrm{P}$ cells) measured connectivity may differ from anatomical overlap (Brown and Hestrin, 2009). The divergence between measured and predicted values suggests that the specificity of synaptic targeting is not fully accounted for by anatomical predictions, and may be shaped by other factors such as the functional relationships among neuronal subnetworks (cf. Kalisman et al., 2005; Shepherd et al., 2005).

\section{Effects of slicing; estimates of in vivo connectivity}

It has been estimated that slicing causes substantial reduction of long-range input and a smaller but still significant reduction of local connectivity (Stepanyants et al., 2009). Our analysis (Figs. 6, 7) indicates that slicing reduced the total connectivity but did not distort the spatial connectivity pattern, at least on the scale we examined $(<300 \mu \mathrm{m})$. Conversely, there is evidence that slicing induces synaptogenesis, because synapse density is greater in sliced than in perfused tissue (Kirov et al., 1999). However, new synapses do not seem to form promiscuously, because connectivity in slice preparations still shows great specificity. For example, in rodent barrel cortex the connection probability is only $\sim 10 \%$ for layer 5 pyramidal cells, but a connection typically comprises 4-8 discrete anatomical synapses (Markram et al., 1997). Thus the loss of synapses due to slicing could produce a reduction in either overall connection probability or average unitary PSP strength. Future network models based on connectivity data from slice experiments may want to take both scenarios into account.

\section{Relationship to functional models of $\mathrm{A} 1$ and other sensory regions}

In previous modeling work we have investigated the local circuitry that might underlie the diverse responses seen in A1 and other sensory regions under experimental conditions using brief auditory stimuli (see above, Introduction). A wide range of cortical response patterns could be accounted for in a model where the local spread of activity varied between the lateral inhibitory and the co-tuned configurations (Oswald et al., 2006; de la Rocha et al., 2008). Either configuration could be generated in a reduced network consisting of P and FS cells, by varying the local and afferent connectivity patterns (de la Rocha et al., 2008; Levy and Reyes, 2011). In this section we discuss the aspects of the data that are most relevant to the reduced model. The potential role of non-FS cells is discussed below.

Two findings are especially relevant to the model. First, the spatial spreads $(\sigma)$ of excitatory and G42 inhibitory connectivity were comparable, ranging from 95 to $114 \mu \mathrm{m}$ (Fig. 4, Table 3). Second, the peak connection probability was substantially less for P-P interconnections than for P-G42 (Figs. 4, 7, Table 3), and PSPs evoked between P cells were relatively weak (Fig. $3 A$ ). Coextensive excitation and inhibition (comparable $\sigma$ ) might cancel each other such that the network could not generate response properties attributable to lateral inhibition (cf. Wehr and Zador, 2003). However, the spread of recurrent excitation would be irrelevant if the magnitude (peak $\mathrm{P}_{\mathrm{C}}$ and unitary EPSP strength) were sufficiently small. While it is not clear which effect predominates from inspection of the data, our recent network simulations indicate that the network configuration is not fixed. Rather, either lateral inhibition or co-tuning can predominate, depending on the spatial spread of thalamic afferents (Levy and Reyes, 2011); narrow and broad afferent input will produce lateral inhibition and co-tuning, respectively. This is a direct consequence of the network architecture; when recurrent $\mathrm{P} \rightarrow \mathrm{P}$ connectivity is sufficiently weak, the network reduces to a simple feedforward model where the responses are dominated by the afferent excitation and the FS $\rightarrow$ P inhibition. Because both broad and narrow afferents may target the same thalamorecipient region (Blasdel and Lund, 1983; Jensen and Killackey, 1987), the same local circuitry may be able to generate diverse response patterns.

Conservatively, the findings apply to frequency tuning in $\mathrm{A} 1$ or other regions of graded variation in receptive field properties, e.g., orientation tuning within a column of V1 (Hubel and Wiesel, 1977). In contrast, somatosensory barrel cortex has a distinctly modular arrangement that reflects the discrete whisker inputs (Petersen, 2007). In layer 4, P cells preferentially target others in the same column (Lübke et al., 2000; Petersen and Sakmann, 2000) and excitation remains confined laterally even when fast inhibition is blocked (Petersen and Sakmann, 2001). With that proviso, our model may be generally applicable in other layers where there is more lateral integration. 


\section{Possible role of non-FS interneurons}

$\mathrm{P} \rightarrow$ GIN PSP trains showed strong facilitation (Fig. 3C, Table 2), in contrast to the other connection types and as has been well documented for $\mathrm{P} \rightarrow$ non-FS interneuron connections in other cortical areas (Thomson et al., 1995; Markram et al., 1998; Reyes et al., 1998). Because EPSPs targeting GIN cells are initially weak, it is likely that GIN cells are quiescent at stimulus onset and do not contribute much to transient responses recorded in vivo with brief stimuli (Wehr and Zador, 2003; Wu et al., 2008) and in vitro (Beierlein et al., 2003). Preliminary simulations incorporating the GIN cell data reported here confirm that non-FS cells do not influence transient network responses (Levy and Reyes, unpublished). Conversely, there is evidence that somatostatin-positive non-FS interneurons are active during states of sustained activity, with firing patterns distinct from those of FS cells (Fanselow et al., 2008; Fanselow and Connors, 2010). Efforts to test the role of non-FS cells and sustained activity in our network model are ongoing.

\section{References}

Bandyopadhyay S, Shamma SA, Kanold PO (2010) Dichotomy of functional organization in the mouse auditory cortex. Nat Neurosci $13: 361-368$

Barbour B, Isope P (2000) Combining loose cell-attached stimulation and recording. J Neurosci Methods 103:199-208.

Beierlein M, Gibson JR, Connors BW (2003) Two dynamically distinct inhibitory networks in layer 4 of the neocortex. J Neurophysiol 90:2987-3000.

Blasdel GG, Lund JS (1983) Termination of afferent axons in macaque striate cortex. J Neurosci 3:1389-1413.

Brown SP, Hestrin S (2009) Intracortical circuits of pyramidal neurons reflect their long-range axonal targets. Nature 457:1133-1136.

Chattopadhyaya B, Di Cristo G, Higashiyama H, Knott GW, Kuhlman SJ, Welker E, Huang ZJ (2004) Experience and activity-dependent maturation of perisomatic GABAergic innervation in primary visual cortex during a postnatal critical period. J Neurosci 24:9598-9611.

Colonnier M (1964) The tangential organization of the visual cortex. J Anat 98:327-344.

Cruikshank SJ, Rose HJ, Metherate R (2002) Auditory thalamocortical synaptic transmission in vitro. J Neurophysiol 87:361-384.

de la Rocha J, Marchetti C, Schiff M, Reyes AD (2008) Linking the response properties of cells in auditory cortex with network architecture: co-tuning versus lateral inhibition. J Neurosci 28:9151-9163.

Dorrn AL, Yuan K, Barker AJ, Schreiner CE, Froemke RC (2010) Developmental sensory experience balances cortical excitation and inhibition. Nature 465:932-936.

Douglas RJ, Koch C, Mahowald M, Martin KA, Suarez HH (1995) Recurrent excitation in neocortical circuits. Science 269:981-985.

Ehret G (1976) Development of absolute auditory thresholds in the house mouse (Mus musculus). J Am Audiol Soc 1:179-184.

Fanselow EE, Connors BW (2010) The roles of somatostatin-expressing (GIN) and fast-spiking inhibitory interneurons in UP-DOWN states of mouse neocortex. J Neurophysiol 104:596-606.

Fanselow EE, Richardson KA, Connors BW (2008) Selective, statedependent activation of somatostatin-expressing inhibitory interneurons in mouse neocortex. J Neurophysiol 100:2640-2652.

Fino E, Yuste R (2011) Dense inhibitory connectivity in neocortex. Neuron 69:1188-1203.

Goldberg JH, Lacefield CO, Yuste R (2004) Global dendritic calcium spikes in mouse layer 5 low threshold spiking interneurones: implications for control of pyramidal cell bursting. J Physiol 558:465-478.

Gupta A, Wang Y, Markram H (2000) Organizing principles for a diversity of GABAergic interneurons and synapses in the neocortex. Science 287:273-278.

Hackett TA, Barkat TR, O’Brien BM, Hensch TK, Polley DB (2011) Linking topography to tonotopy in the mouse auditory thalamocortical circuit. J Neurosci 31:2983-2995.

Halasy K, Buhl EH, Lörinczi Z, Tamás G, Somogyi P (1996) Synaptic target selectivity and input of GABAergic basket and bistratified interneurons in the CAl area of the rat hippocampus. Hippocampus 6:306-329.
Hellwig B (2000) A quantitative analysis of the local connectivity between pyramidal neurons in layers $2 / 3$ of the rat visual cortex. Biol Cybern $82: 111-121$

Holmgren C, Harkany T, Svennenfors B, Zilberter Y (2003) Pyramidal cell communication within local networks in layer $2 / 3$ of rat neocortex. J Physiol 551:139-153.

Hromádka T, Deweese MR, Zador AM (2008) Sparse representation of sounds in the unanesthetized auditory cortex. PLoS Biol 6:e16.

Huang CL, Winer JA (2000) Auditory thalamocortical projections in the cat: laminar and areal patterns of input. J Comp Neurol 427:302-331.

Hubel DH, Wiesel TN (1977) Ferrier lecture. Functional architecture of macaque monkey visual cortex. Proc R Soc Lond B Biol Sci 198:1-59.

Jensen KF, Killackey HP (1987) Terminal arbors of axons projecting to the somatosensory cortex of the adult rat. I. The normal morphology of specific thalamocortical afferents. J Neurosci 7:3529-3543.

Kalisman N, Silberberg G, Markram H (2003) Deriving physical connectivity from neuronal morphology. Biological Cybernetics 88:210-218.

Kalisman N, Silberberg G, Markram H (2005) The neocortical microcircuit as a tabula rasa. Proc Natl Acad Sci U S A 102:880-885.

Kawaguchi Y, Kubota Y (1993) Correlation of physiological subgroupings of nonpyramidal cells with parvalbumin- and calbindinD28kimmunoreactive neurons in layer $\mathrm{V}$ of rat frontal cortex. J Neurophysiol 70:387-396.

Kawaguchi Y, Kubota Y (1997) GABAergic cell subtypes and their synaptic connections in rat frontal cortex. Cereb Cortex 7:476-486.

Kirov SA, Sorra KE, Harris KM (1999) Slices have more synapses than perfusion-fixed hippocampus from both young and mature rats. J Neurosci 19:2876-2886.

LeVay S (1986) Synaptic organization of claustral and geniculate afferents to the visual cortex of the cat. J Neurosci 6:3564-3575.

Levy RB, Reyes AD (2011) Coexistence of lateral and co-tuned inhibitory configurations in cortical networks. PLoS Comput Biol 7:e1002161.

Lübke J, Egger V, Sakmann B, Feldmeyer D (2000) Columnar organization of dendrites and axons of single and synaptically coupled excitatory spiny neurons in layer 4 of the rat barrel cortex. J Neurosci 20:5300-5311.

Ma Y, Hu H, Berrebi AS, Mathers PH, Agmon A (2006) Distinct subtypes of somatostatin-containing neocortical interneurons revealed in transgenic mice. J Neurosci 26:5069-5082.

Marin-Padilla M (1969) Origin of the pericellular baskets of the pyramidal cells of the human motor cortex: A Golgi study. Brain Res 14:633-646.

Markram H, Lübke J, Frotscher M, Roth A, Sakmann B (1997) Physiology and anatomy of synaptic connections between thick tufted pyramidal neurones in the developing rat neocortex. J Physiol 500:409-440.

Markram H, Wang Y, Tsodyks M (1998) Differential signaling via the same axon of neocortical pyramidal neurons. Proc Natl Acad Sci U S A 95:5323-5328.

McGarry LM, Packer AM, Fino E, Nikolenko V, Sippy T, Yuste R (2010) Quantitative classification of somatostatin-positive neocortical interneurons identifies three interneuron subtypes. Front Neural Circuits 4:12.

Metherate R, Aramakis VB (1999) Intrinsic electrophysiology of neurons in thalamorecipient layers of developing rat auditory cortex. Brain Res Dev Brain Res 115:131-144.

Müller-Preuss P, Mitzdorf U (1984) Functional anatomy of the inferior colliculus and the auditory cortex: current source density analyses of clickevoked potentials. Hear Res 16:133-142.

Nikolenko V, Fino E, Yuste R (2011) Two-photon mapping of neural circuits. Cold Spring Harb Protoc. doi:10.1101/pdb.top11.

Oliva AA Jr, Jiang M, Lam T, Smith KL, Swann JW (2000) Novel hippocampal interneuronal subtypes identified using transgenic mice that express green fluorescent protein in GABAergic interneurons. J Neurosci 20:3354-3368.

Oswald AM, Reyes AD (2008) Maturation of intrinsic and synaptic properties of layer $2 / 3$ pyramidal neurons in mouse auditory cortex. J Neurophysiol 99:2998-3008.

Oswald AM, Reyes AD (2011) Development of inhibitory timescales in auditory cortex. Cereb Cortex 21:1351-1361.

Oswald AM, Schiff ML, Reyes AD (2006) Synaptic mechanisms underlying auditory processing. Curr Opin Neurobiol 16:371-376.

Oswald AM, Doiron B, Rinzel J, Reyes AD (2009) Spatial profile and differential recruitment of $\mathrm{GABA}_{\mathrm{B}}$ modulate oscillatory activity in auditory cortex. J Neurosci 29:10321-10334.

Otsuka T, Kawaguchi Y (2009) Cortical inhibitory cell types differentially 
form intralaminar and interlaminar subnetworks with excitatory neurons. J Neurosci 29:10533-10540.

Packer AM, Yuste R (2011) Dense, unspecific connectivity of neocortical parvalbumin-positive interneurons: a canonical microcircuit for inhibition? J Neurosci 31:13260-13271.

Perin R, Berger TK, Markram H (2011) A synaptic organizing principle for cortical neuronal groups. Proc Natl Acad Sci U S A 108:5419-5424.

Peters A, Payne BR (1993) Numerical relationships between geniculocortical afferents and pyramidal cell modules in cat primary visual cortex. Cereb Cortex 3:69-78.

Peters A, Payne BR, Budd J (1994) A numerical analysis of the geniculocortical input to striate cortex in the monkey. Cereb Cortex 4:215-229.

Petersen CC (2007) The functional organization of the barrel cortex. Neuron 56:339-355.

Petersen CC, Sakmann B (2000) The excitatory neuronal network of rat layer 4 barrel cortex. J Neurosci 20:7579-7586.

Petersen CC, Sakmann B (2001) Functionally independent columns of rat somatosensory barrel cortex revealed with voltage-sensitive dye imaging. J Neurosci 21:8435-8446.

Reyes A, Lujan R, Rozov A, Burnashev N, Somogyi P, Sakmann B (1998) Target-cell-specific facilitation and depression in neocortical circuits. Nat Neurosci 1:279-285.

Rose HJ, Metherate R (2005) Auditory thalamocortical transmission is reliable and temporally precise. J Neurophysiol 94:2019-2030.

Rudy B, Fishell G, Lee S, Hjerling-Leffler J (2011) Three groups of interneurons account for nearly $100 \%$ of neocortical GABAergic neurons. Dev Neurobiol 71:45-61.

Sally SL, Kelly JB (1988) Organization of auditory cortex in the albino rat: sound frequency. J Neurophysiol 59:1627-1638.

Schreiner CE, Read HL, Sutter ML (2000) Modular organization of frequency integration in primary auditory cortex. Annu Rev Neurosci 23:501-529.

Shapley R, Hawken M, Xing D (2007) The dynamics of visual responses in the primary visual cortex. Prog Brain Res 165:21-32.

Shepherd GM, Stepanyants A, Bureau I, Chklovskii D, Svoboda K (2005) Geometric and functional organization of cortical circuits. Nat Neurosci 8:782-790.

Sompolinsky H, Shapley R (1997) New perspectives on the mechanisms for orientation selectivity. Curr Opin Neurobiol 7:514-522.

Song L, McGee J, Walsh EJ (2006) Frequency- and level-dependent changes in auditory brainstem responses (ABRS) in developing mice. J Acoust Soc Am 119:2242-2257.

Stepanyants A, Chklovskii DB (2005) Neurogeometry and potential synaptic connectivity. Trends Neurosci 28:387-394.

Stepanyants A, Martinez LM, Ferecskó AS, Kisvárday ZF (2009) The frac- tions of short- and long-range connections in the visual cortex. Proc Natl Acad Sci U S A 106:3555-3560.

Stuart GJ, Dodt HU, Sakmann B (1993) Patch-clamp recordings from the soma and dendrites of neurons in brain slices using infrared video microscopy. Pflügers Arch 423:511-518.

Suga N, Simmons JA, Jen PH (1975) Peripheral specialization for fine analysis of doppler-shifted echoes in the auditory system of the "CF-FM" bat Pteronotus parnellii. J Exp Biol 63:161-192.

Suga N, Zhang Y, Yan J (1997) Sharpening of frequency tuning by inhibition in the thalamic auditory nucleus of the mustached bat. J Neurophysiol 77:2098-2114

Sun YJ, Wu GK, Liu BH, Li P, Zhou M, Xiao Z, Tao HW, Zhang LI (2010) Fine-tuning of pre-balanced excitation and inhibition during auditory cortical development. Nature 465:927-931.

Takesian AE, Kotak VC, Sanes DH (2010) Presynaptic GABA(B) receptors regulate experience-dependent development of inhibitory short-term plasticity. J Neurosci 30:2716-2727.

Thomson AM, Deuchars J, West DC (1993) Single axon excitatory postsynaptic potentials in neocortical interneurons exhibit pronounced paired pulse facilitation. Neuroscience 54:347-360.

Thomson AM, West DC, Deuchars J (1995) Properties of single axon excitatory postsynaptic potentials elicited in spiny interneurons by action potentials in pyramidal neurons in slices of rat neocortex. Neuroscience 69:727-738

Wang Y, Toledo-Rodriguez M, Gupta A, Wu C, Silberberg G, Luo J, Markram $\mathrm{H}$ (2004) Anatomical, physiological and molecular properties of Martinotti cells in the somatosensory cortex of the juvenile rat. J Physiol 561:65-90.

Wehr M, Zador AM (2003) Balanced inhibition underlies tuning and sharpens spike timing in auditory cortex. Nature 426:442-446.

White EL (1989) Cortical circuits. Boston: Birkhäuser.

Williams SM, Goldman-Rakic PS, Leranth C (1992) The synaptology of parvalbumin-immunoreactive neurons in the primate prefrontal cortex. J Comp Neurol 320:353-369.

Wong WC (1967) The tangential organization of dendrites and axons in three auditory areas of the cat's cerebral cortex. J Anat 101:419-433.

Wu GK, Arbuckle R, Liu BH, Tao HW, Zhang LI (2008) Lateral sharpening of cortical frequency tuning by approximately balanced inhibition. Neuron 58:132-143.

Xiang Z, Huguenard JR, Prince DA (1998) Cholinergic switching within neocortical inhibitory networks. Science 281:985-988.

Young ED, Brownell WE (1976) Responses to tones and noise of single cells in dorsal cochlear nucleus of unanesthetized cats. J Neurophysiol 39:282300 . 